\title{
Ensino de Ciências a partir da Problematização: percepções de educandos acerca do ciclo de vida da Drosophila melanogaster
}

Science Teaching through Problematization: students' perceptions about Drosophila melanogaster

\author{
life cycle \\ Enseñar Ciencias a través de la Problematización: Percepciones de los estudiantes sobre el ciclo de \\ vida de Drosophila melanogaster
}

\section{Resumo}

O presente estudo utilizou a Metodologia da Problematização com o Arco de Maguerez (MP/AM) para verificar a percepção de estudantes sobre o ciclo de vida dos insetos. Para isso, foi utilizada como modelo a Drosophila melanogaster, popularmente conhecida como mosca da fruta. Além de sua utilização como modelo experimental, esse inseto vem sendo empregado como modelo didático de apoio no processo de ensino e aprendizagem. Esta atividade foi desenvolvida com estudantes do oitavo ano de uma escola pública de ensino fundamental da cidade de Uruguaiana/RS. Os dados foram coletados por meio de anotações feitas pelos participantes durante as atividades e após foram analisados e categorizados. A atividade foi desenvolvida ao longo de três semanas, divididas em 2 horas/aula por semana, na componente curricular de Ciências. Os resultados indicaram que a MP/AM, em conjunto com o modelo didático proposto, serviu como facilitadora para o processo de ensino-aprendizagem. Ainda, a utilização da MP/AM, aliada ao modelo D. melanogaster, tornou o ensino do ciclo de vida dos insetos mais interessante e dinâmico, visto que possibilitou aos educandos desenvolverem habilidades como criticidade e autonomia. Dessa forma, inferimos que estratégias diversificadas para o Ensino de Ciências podem servir como propulsoras para a melhoria da aprendizagem e consequentemente para a formação de sujeitos mais aptos a problematizar e analisar de forma crítica o mundo ao seu redor.

Palavras-chave: Arco de Maguerez; Ensino de ciências; Metodologia da problematização; Mosca da fruta.

\begin{abstract}
The present study used the Problematization Methodology with the Maguerez Arch (MP/AM) to verify students' perception about the insect's life cycle. For this, Drosophila melanogaster, popularly known as fruit fly, was used as model. In addition to its use as an experimental model, this insect has been used as a didactic model to support the teaching and learning process. This activity was developed with eighth grade students from a public elementary school in Uruguaiana/RS city. Data were collected through notes taken by participants during the activities, and these were analyzed and categorized. The activity was developed over three weeks, divided into 2 hours/class per week, in the curricular component of science. Results indicated that MP/AM, together with the proposed didactic model, served as a facilitator for the teaching-learning process. Furthermore, the use of MP/AM, allied to D. melanogaster model, made the insects life cycle teaching more interesting and dynamic, as it enabled students to develop skills such
\end{abstract}


as criticality and autonomy. In this way, we infer that diversified strategies for Science Teaching can serve as propellers for the learning improvement, and consequently, for the formation of subjects more able to problematize and critically analyze the world around them.

Keywords: Maguerez Arch; Science teaching; Problematization methodology; Fruit fly.

\section{Resumen}

El presente estudio utilizó la Metodología de Problematización con el Arco de Maguerez (MP/AM) para verificar la percepción de los estudiantes sobre el ciclo de vida de los insectos. Como modelo experimental se utilizó la Drosophila melanogaster, conocida popularmente como mosca de la fruta. Además de su uso como modelo experimental, este insecto se ha utilizado como modelo didáctico para apoyar el proceso de enseñanza y aprendizaje. Esta actividad fue desarrollada con estudiantes de octavo grado de una escuela pública en la ciudad de Uruguayana/RS. Los datos fueron recolectados a través de apuntes tomados por los participantes durante las actividades y estos fueron analizados y categorizados. La actividad se desarrolló durante tres semanas, divididas en 2 horas/clase por semana, en el componente curricular de Ciencias. Los resultados indicaron que la MP/AM, junto con el modelo didáctico propuesto, sirvió como facilitador del proceso de enseñanza-aprendizaje. Además, el uso de MP/AM, aliado al modelo de $D$. melanogaster, hizo más interesante y dinámica la enseñanza del ciclo de vida de los insectos, ya que permitió a los estudiantes desarrollar habilidades como la criticidad y la autonomía. De esta forma, inferimos que estrategias diversificadas para la Enseñanza de las Ciencias pueden servir como propulsores para la mejora de los aprendizajes y, en consecuencia, para la formación de sujetos más capaces de problematizar y analizar críticamente el mundo que les rodea.

Palabras clave: Arco de Maguerez; Enseñanza de las ciencias; Metodología de problematización; Mosca de la fruta.

\section{Introdução}

O cenário atual da educação básica brasileira é de profundas transformações, decorrentes do modelo de sociedade em que vivemos. Com isso, novas tendências pedagógicas apontam para a necessidade de se repensar práticas escolares antes pautadas no modelo tradicional de ensino, onde as "as ações de ensino apresentam-se centradas na transmissão de conhecimentos pelo professor ao aluno" (Prado et al., 2012 p.173). Nesta perspectiva, o educador é o único responsável pela condução do processo de ensino e aprendizagem e, o estudante sujeito passivo, apenas recebendo as informações que lhe são apresentadas. Diante disso, torna-se essencial desenvolver estratégias de ensino que superem o modelo tradicional de ensino/aprendizagem vigente nos ambientes escolares ainda hoje.

Ao adotar práticas pedagógicas ativas, torna-se essencial que o educador compreenda sua importância enquanto mediador do conhecimento. Assim, além de ter conhecimento em assuntos específicos, o docente deve ter uma visão humanista abrangente, com o objetivo de considerar os conhecimentos prévios dos educandos e os utilizar para facilitar a compreensão de novos conhecimentos (Shulman, 2014). Para isso, deve-se levar em consideração como os educandos aprendem e como métodos diversificados de ensino podem facilitar a aprendizagem. Para além da aprendizagem, os conhecimentos apreendidos devem promover o reconhecimento do aluno como um ser que modifica, (re)constrói e interfere na sua realidade.

Nesta ótica, suscita-se a necessidade de repensar e refletir sobre os objetivos dos processos educacionais (Viçosa et al., 2016; Martins et al., 2020). Estes objetivos devem pautar a integração entre educandos, educadores e a sociedade na busca pela construção de novos conhecimentos. E, para atingir estes objetivos, novas propostas metodológicas também precisam ser pensadas a fim de superar os obstáculos postos no âmbito educacional, sobretudo, no Ensino de Ciências.

O entendimento deve ser o de que "o aprendizado se dá pela interação professor/estudantes/conhecimento" (Pinto \& Uieda, 2007, p. 507). Nesse sentido, é necessário que o educador leve em consideração os conhecimentos prévios dos estudantes, pois ao considerá-los, o processo de aprendizagem torna-se mais efetivo (Liu et al., 2018). Pode-se compreender que o educando reconstrói suas percepções de mundo ao entrar em contato com a visão trazida pela Ciência, a partir da mediação realizada pelo educador.

Ao enfatizar a aprendizagem e propiciar a formação crítica dos educandos, é essencial que os educadores sempre repensem as metodologias de ensino, pois o educando necessita assumir uma postura cada vez mais ativa (Nascimento et al., 
2022). Ainda, os educadores podem complementar o ensino tradicional com a utilização de Metodologias Ativas (MA) de aprendizagem. As MA, de acordo com Morán (2015), estão fundamentadas na pedagogia problematizadora, estimulando o educando a assumir uma postura ativa e autônoma em seu processo de aprender. Nesta perspectiva, Berbel (2016) aponta que os educandos desenvolvem o processo de aprender por meio de experiências reais ou simuladas, solucionando desafios decorrentes das atividades essenciais da prática social, em diferentes contextos.

Dentre as MA existentes, ressalta-se a Metodologia da Problematização (MP), "que tem como objetivo instigar o estudante mediante problemas, pois assim ele tem a possibilidade de examinar, refletir, posicionar-se de forma crítica" (Borges e Alencar, 2014 p. 120). Ao pensarmos no Ensino de Ciências como a área do conhecimento que propicia experiências e contempla o contexto social dos educandos, depreende-se que há uma ligação entre o ensino de ciências e a MP. Tendo em vista que MP é utilizada em situações nas quais os temas estejam relacionados com a vida em sociedade, a utilização conjunta com o Arco Maguerez como método de ensino e aprendizagem propicia a efetivação da MP.

Segundo Berbel (2016), o Arco de Maguerez foi criado na década de 70 por Charles Maguerez e reelaborado em 1977 por Bordenave e Pereira. A confluência entre a MP e o Arco de Maguerez ocorreu em 1992, em uma perspectiva de transformar o processo de ensino. Essa proposição contempla características principais, das quais são a problematização e a busca de soluções para os problemas. Diante do exposto, apresentamos uma proposta de ensino sobre a o ciclo de vida dos insetos. Essa atividade foi pensada e organizada de acordo com MP utilizada em conjunto com o Arco de Maguerez (MP/AM). A referida proposta foi aplicada em uma turma de $8^{\circ}$ ano dos anos finais do Ensino Fundamental, na qual buscou-se investigar as percepções dos educandos acerca do ciclo de vida da mosca Drosophila melanogaster.

\subsection{Ensino de Ciências}

Atualmente, o Ensino de Ciências tem urgência em ofertar métodos de ensino que aprimorem a capacidade de os educandos em analisar o mundo ao seu redor e desenvolver pensamento crítico. Porém, Vasconcelos \& Neres (2021) apontam que as escolas ainda utilizam metodologias tradicionais e descontextualizadas, fazendo com que os estudantes se tornem meros memorizadores de conhecimentos.

Ainda, a abordagem acerca do Ensino de Ciências requer um planejamento de um ensino eficaz para o entendimento dos conhecimentos científicos no cotidiano dos sujeitos (Vasconcelos \& Neres, 2021). Neste cenário, popularizar o conhecimento acerca da ciência torna-se essencial para que os educandos possam entender melhor a sociedade em que estão inseridos.

Corroborando, Chassot (2003) ressalta que a alfabetização científica favorece para que os sujeitos entendam a leitura do mundo e que compreendam a necessidade de transformá-lo positivamente. Assim, o Ensino de Ciências é imprescindível para a integração social do ser humano, além de contribuir para que os sujeitos compreendam melhor o mundo e constituam-se sujeitos cientificamente preparados e conscientes. Para que isso aconteça, cabe ao educador buscar estratégias para a melhoria do processo de ensino e aprendizagem. O papel do educador é estimular a curiosidade dos educandos, de modo que os sujeitos sintam a necessidade de investigar, problematizar e questionar assuntos relacionados à essa área do saber. Para Lima et al., (2016, p. 21):

[...]organizam-se atividades experimentais na perspectiva construtivista levando-se em consideração o conhecimento prévio dos alunos. Adotar essa postura construtivista significa aceitar que nenhum conhecimento é assimilado do nada, mas que deve ser construído ou reconstruído pela estrutura de conceitos já existentes.

Mas como ensinar Ciências? Como despertar o interesse dos educandos para essa área? Souza et al. (2022) afirmam que o Ensino de Ciências enfrenta obstáculos no cenário atual, uma vez que os estudantes apresentam dificuldades no 
entendimento e assimilação acerca dos conteúdos dessa área. Dessa forma, os autores supracitados ressaltam que é imprescindível a utilização de recursos didáticos que proporcionem a compreensão de conteúdos voltados para o Ensino de Ciências.

Ainda, nesta vertente, Somavilla e Zara (2016) destacam a relevância de práticas experimentais na área das ciências, sendo um processo permanente e relacionado ao que existe no universo. Estas práticas podem influenciar e impactar diretamente no cotidiano dos estudantes e conduzir a questionamentos e investigações futuras. Assim, o processo de ensino acerca da Ciência deve ter o objetivo de formar cidadãos críticos e reflexivos, que compreendam a importância da mesma. Ainda, os sujeitos alfabetizados cientificamente devem ser capazes de participar ativamente das discussões sobre Ciência que ocorrem na sociedade, de modo a transformá-la em algo melhor (Chassot, 2003).

\subsection{Metodologia da Problematização e Arco de Maguerez}

A metodologia da Problematização com o arco de Maguerez (MP/AM) parte de uma crítica ao ensino tradicional e propõe um ensino diferenciado, cuja problematização da realidade e a busca por soluções possibilitam o desenvolvimento do raciocínio crítico dos estudantes. Assim, a utilização dessa metodologia é conveniente sempre que os conteúdos abordados estejam relacionados com o meio em que os estudantes vivem (Berbel, 1998). Desta forma, relacionar os conteúdos ao dia a dia dos educandos é uma das maneiras de facilitar a compreensão de mundo, assim como tornar o Ensino de Ciências mais atrativo.

O desenvolvimento dessa metodologia contempla cinco etapas envolvendo investigação, problematização e intervenção. Em síntese, de acordo com Berbel (2016), o arco de Maguerez tem como ponto de partida a observação da realidade, segue na elaboração de pontos chaves, na teorização, no levantamento das hipóteses de solução e finda na aplicação à realidade, formando nesse conjunto um arco, como pode ser observado na Figura 1.

Figura 1. Representação do Arco de Maguerez.

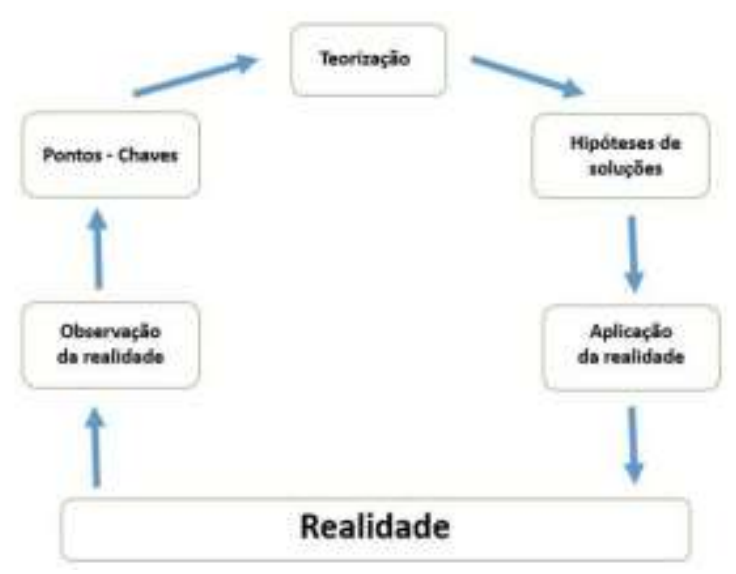

Fonte: Elaborado pelos autores, baseado em Berbel (2016).

O esquema do Arco de Maguerez utilizado na Metodologia da Problematização é sintetizado por Berbel (1998), o qual tem como ponto de partida a realidade observada por diversos ângulos. Deste modo, os educandos podem identificar os problemas existentes ao observarem a realidade. Abaixo, detalhamos as cinco etapas supracitadas:

$>$ Observação da realidade: É baseada no conjunto de informações assimilados durante a observação de uma problemática real. 
Pontos-chave: Nesta etapa ocorre a reflexão sobre a problemática observada e as possíveis causas da mesma.

$>$ Teorização: Consiste em investigar/estudar acerca do causador do problema previamente elencado nos pontos-chave, com intuito de compreendê-lo e encontrar meios para solucioná-lo. Esses dados devem ser analisados e discutidos, sempre tendo como tema central a problemática.

$>$ Hipóteses de solução: Incide em construir por meio de investigações críticas e reflexivas alternativas para solução do problema encontrado na etapa da observação.

$>$ Aplicação à realidade: Nesta última etapa aplica-se na prática todas as hipóteses criadas para solução da problemática, com um retorno à realidade investigada.

Para Colombo e Berbel (2007), a etapa da aplicação permite aos sujeitos testar as soluções encontradas, contemplando o comprometimento do pesquisador com o estudo, ao voltar à mesma realidade transformando-a positivamente em algum grau. Nesse cenário, entendemos que a MP/AM busca desenvolver a criticidade em estudantes, para que estes sujeitos atuem de modo crítico e reflexivo na sociedade. Ainda, o uso da MP/AM favorece a utilização de diferentes estratégias de ensino e aprendizagem, possibilitando fomentar as práticas educativas. Desta forma, a MP/AM fomenta o interesse pelo conhecimento científico e o aprendizado prazeroso e efetivo. Em nosso estudo, em conjunto com a MP/AM, utilizamos como estratégia um modelo didático para o estudo do ciclo de vida dos insetos, a Drosophila melanogaster.

A Drosophila melanogaster é conhecida popularmente como mosca da fruta. Este inseto possui em média de $3 \mathrm{~mm}$ à $4 \mathrm{~mm}$ de comprimento e se reproduz facilmente. Seu ciclo de vida é curto durando cerca de 26 dias (Borror \& Delong, 1969). Gomes (2001) destaca o ciclo da mosca em seis fases: $1^{\circ}$ fase (eclosão do ovo), $2^{\circ}$ fase (primeira forma de larva), $3^{\circ}$ fase (segunda fase de larva), $4^{\circ}$ fase (terceira fase de larva), $5^{\circ}$ fase (estágio de pré pupa) e $6^{\circ}$ fase (estágio de pupa, onde ocorre a eclosão do indivíduo), como mostra a Figura 2.

Figura 2. Ciclo de vida da Drosophila melanogaster.

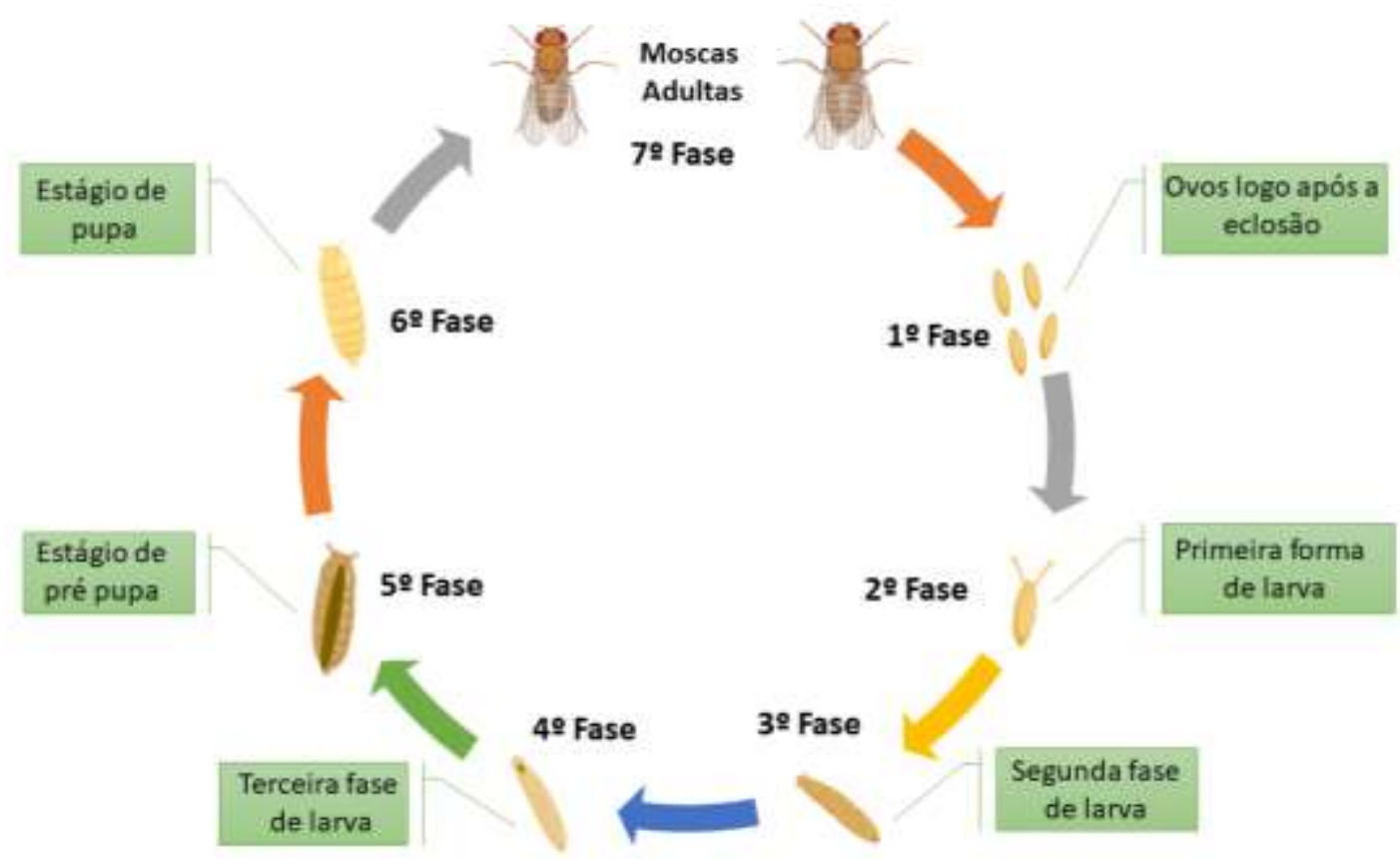

Fonte: Elaborado pelos autores. 
Após eclosão, o indivíduo atingirá sua maturidade sexual após 12 horas. É possível identificar machos e fêmeas a olho nu: no macho, o abdômen é listrado e na porção final do mesmo existe uma pigmentação preta, enquanto na fêmea não existe essa pigmentação (Gomes, 2001). Devido a estas características, essa espécie tem sido amplamente utilizada como apoio no processo de ensino e aprendizagem. $\mathrm{O}$ uso deste inseto decorre do seu fácil manejo, alta taxa de reprodução e baixo custo econômico e ciclo de vida curto (Rocha et al., 2013).

Essa somatória possibilita a utilização em aulas práticas que visam despertar o interesse dos educandos para o ciclo de vida dos insetos ou ainda para modelos experimentais. A utilização destes insetos com modelo didático pode contribuir com o processo de aprendizagem, pois muitos educandos têm dificuldades em assimilar conteúdos quando apresentados de forma abstrata e descontextualizada da realidade (Salgueiro et al., 2018). Com isso, pode-se dizer que o uso das moscas, como modelo didático, pode ser eficaz tanto na prática docente quanto na experimentação.

De fato, uma das possibilidades de desenvolver a prática científica na escola é através da experimentação, que pode ser desenvolvida em diferentes etapas com os educandos, contemplando diferentes metodologias. De acordo com Taha et al., (2016), estas metodologias podem perpassar a experimentação ilustrativa, que visa demonstrar conceitos discutidos anteriormente. Ainda, existe a experimentação investigativa, que possui o mesmo caráter da investigação científica, em que o educando faz o levantamento do problema, elabora hipóteses, realiza o experimento para comprovar suas hipóteses e organiza os resultados para fazer suas próprias conclusões.

\section{Metodologia}

A presente investigação caracteriza-se por ser qualitativa e possuir caráter exploratório, que segundo Gil (2002), é baseada em estudos de caso, entrevistas com pessoas, levantamento bibliográfico e análise de exemplos de compreensão. A proposta foi desenvolvida durante três semanas consecutivas em uma turma do oitavo ano de uma Escola Municipal de Ensino Fundamental na cidade de Uruguaiana/RS.

Participaram vinte e quatro educandos com média de idade de doze anos. Os participantes e seus responsáveis assinaram o Termo de Consentimento Livre e Esclarecido e o Termo de Assentimento do Menor. A realização da proposta foi aprovada pelo Comitê de Ética em Pesquisa, pela direção da escola e pela docente de Ciências da escola. Para preservar a identidade dos participantes, os estudantes foram numerados de 01 a 24.

A atividade foi desenvolvida no decorrer das três semanas, divididas em $2 \mathrm{~h} /$ aula semanais, na componente curricular de Ciências. A descrição de cada etapa da atividade está apresentada no Quadro 1.

Quadro 1: Descrição das atividades.

\begin{tabular}{|c|l|}
\hline ETAPA & \multicolumn{1}{c|}{ ATIVIDADE } \\
\hline $1^{\mathrm{a}}$ semana & Observação da realidade; Pontos-chave. \\
\hline $2^{\mathrm{a}}$ semana & Observação da realidade; Teorização. \\
\hline $3^{\mathrm{a}}$ semana & Hipóteses de solução e Aplicação na realidade. \\
\hline
\end{tabular}

Fonte: Elaborado pelos autores.

No Quadro 1 pode-se observar o delineamento das atividades baseadas nos fundamentos da MP/AM. Para o registro das observações, os educandos receberam uma folha sulfite personalizada com um espaço específico para desenhar e um espaço que poderiam registar de forma discursiva suas percepções. A cada etapa das atividades desenvolvidas os educandos realizaram novos registros. Ainda, os estudantes obtiveram um feedback sobre os registros anteriores. Desta forma, os 
educandos poderiam rever suas anotações, retomar suas concepções e (re)construir seus conhecimentos.

Na primeira semana foi realizada uma roda de conversa e apresentações entre os educandos e os pesquisadores, com a intenção de os mesmos sentirem-se mais acolhidos e participativos no decorrer das atividades. A primeira semana consistiu em observação. Os estudantes foram apresentados à alguns materiais de laboratório (vidrarias, falcons, meios de cultura) e receberam orientação sobre a importância do registro de todas as observações das etapas que viriam a seguir. Na sequência, foram convidados a observar frascos que continham meio de cultura com as moscas adultas dentro. Após a observação, as moscas foram retiradas dos frascos contendo o meio de cultura, de modo que o frasco ficou vazio. Nesta etapa, os educandos foram instigados a responder sobre como surgem as moscas? E como é o ciclo de vida delas? Após essa etapa, foram indicados aos discentes materiais científicos para auxiliar na busca por respostas para essas questões. Entre eles, cita-se artigos científicos de fácil compreensão considerando o nível de escolaridade dos participantes, livros e endereços eletrônicos sobre o tema.

$\mathrm{Na}$ segunda semana foram realizadas novas observações e os estudantes foram orientados a desenhar o que observavam. Neste período, os educandos identificaram que os frascos, esvaziados na semana anterior, apresentavam os primeiros estágios de larvas e algumas pupas. Na sequência, os estudantes foram instigados a responder como as larvas surgiram no pote. Nesse momento, também deveriam registrar por escrito o que eles analisaram. Cabe ressaltar, que nessa fase foi realizada a etapa da teorização, sob mediação da docente responsável pela componente curricular de Ciências. Os pesquisadores colaboraram com a disponibilização de materiais científicos impressos para os educandos. Também foi proposto que em grupos realizassem leituras e buscassem argumentos para construção de hipóteses.

Na última semana da atividade os educandos deram sequência em seus registros e formularam hipóteses sobre o "ressurgimento" das moscas nos frascos, baseados nas leituras científicas realizadas na etapa anterior. Essas hipóteses foram apresentadas aos demais colegas resultando em problematização e sistematização do tema abordado. Os resultados obtidos, a partir das anotações dos participantes, foram analisados e categorizados.

\section{Resultados e Discussão}

A partir do desenvolvimento das atividades obteve-se os seguintes resultados, explicitados no Quadro 2: 
Quadro 2: Atividade desenvolvida a partir da MP/AM;

\begin{tabular}{|c|c|}
\hline ETAPAS DO ARCO & DESCRIÇÃO DAS ATIVIDADES \\
\hline Observação da realidade & $\begin{array}{l}\text { A observação foi registrada em desenhos (Figura } 3 \text { ) e descrita conforme segue: } \\
\text { "Tinha um frasco com moscas e soltaram as moscas". } \\
\text { "A professora pegou o pote e conectou um funil com falcon debaixo do } \\
\text { pote colocou uma caminha e virou as moscas elas foram para o falcon e o pote } \\
\text { ficou vazio". } \\
\text { "As moscas foram libertas e o frasco ficou vazio"; } \\
\text { "Primeiro vimos as moscas e depois a professora tirou as moscas do } \\
\text { vidro e colocou no falcon". }\end{array}$ \\
\hline Pontos-chave & $\begin{array}{l}\text { Os pesquisadores questionaram os estudantes com as seguintes perguntas: } \\
\text { "O que você acha que tem dentro do vidro?" } \\
\text { "Você acha que existe diferença entre os 'pontos' claros e os escuros?" }\end{array}$ \\
\hline $\begin{array}{l}\text { Teorização (aulas* e material } \\
\text { teórico fornecido) }\end{array}$ & $\begin{array}{l}\text { Nas aulas foram trabalhados os seguintes temas: } \\
\text { - Artrópodes } \\
\text {-Insetos, ciclo de vida } \\
\text {-Metamorfose } \\
\text { (*As aulas foram conduzidas pela professora de Ciências) }\end{array}$ \\
\hline Hipóteses de solução & $\begin{array}{l}\text { O acompanhamento dessa etapa se deu através do registro escrito dos estudantes, } \\
\text { conforme segue: } \\
\text { "As moscas saíram, mas deixaram ovos, deles sairam as larvas e delas } \\
\text { já tem mosquinhas". } \\
\text { "As moscas foram retiradas pela professora e elas deixaram os ovos e os } \\
\text { ovos eclodiram e viraram larvas". } \\
\text { "As moscas que estão agora vieram das outras moscas que colocaram } \\
\text { ovos no vidro". } \\
\text { "Dentro do pote tem farinha, os ovos se abriram e se transformam em } \\
\text { larvas, que se transformam em moscas". }\end{array}$ \\
\hline Aplicação na realidade & $\begin{array}{l}\text { Nessa etapa, foi observado se os estudantes eram capazes de aplicar os conhecimentos } \\
\text { adquiridos em outras situações como, por exemplo, a outros seres vivos: } \\
\text { "Nós observamos os ovos de mosca que se desenvolveram em } 2 \text { dias isso } \\
\text { se chama ciclo, vimos que elas estão fermentando e querem sair do vidro para } \\
\text { pegar oxigênio e elas estão quase morrendo". } \\
\text { "Eu estou vendo o vidro com moscas e ácaros e umas larvas, os pontos } \\
\text { escuros são as moscas que não saiu e pontos claros saiu a mosca". } \\
\text { "As moscas surgiram dos ovos que eclodiram". }\end{array}$ \\
\hline
\end{tabular}

Fonte: Elaborado pelos autores.

Além do registro escrito, os estudantes foram incentivados a registrar em forma de desenhos suas observações. A Figura 3 apresenta um recorte de uma das ilustrações realizadas:

Figura 3. Observação da realidade.

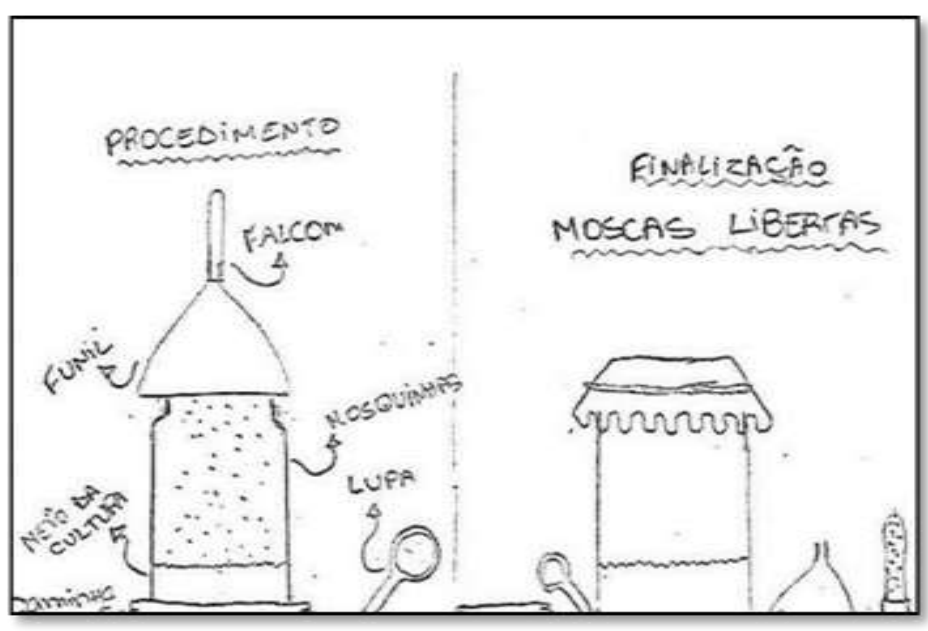

Fonte: Ilustração realizada pelos educandos. 
Ainda, nesse mesmo dia, os educandos foram questionados a responder "De onde vem as moscas". A partir das análises das respostas dos educandos percebeu-se que inicialmente possuem visão criacionista e de geração espontânea. De acordo com Almeida (2012), essa percepção criacionista está ligada ao que diz na bíblia, que Deus criou tudo o que existe no universo. Os educandos também associam o surgimento das moscas como algo mágico, essas respostas podem ser observadas abaixo:

A8: "As moscas vieram de Deus"

A16: "As moscas nascem do lixo"

A 5: "As moscas vêm da comida estragada"

A 22: "Elas nasceram da comida que tá dentro do frasco"

Nesse sentido, se faz necessário levar em consideração o que cada educando traz de bagagem para a sala de aula, servindo assim, como apoio no processo de ensino e aprendizagem. Para alcançar a aprendizagem é preciso que o educador saiba o que o educando tem de conhecimentos prévios e, a partir disso, mediar a construção de novos níveis de conhecimento (Folmer, 2007). Ainda, o autor aponta "os conhecimentos adquiridos pelos estudantes fora da escola, conhecimentos esses que, juntamente com suas concepções e atitudes face à Ciência, influenciam fortemente a aprendizagem” (Folmer, 2007, p 15).

Corroborando com nosso estudo, Santos e Macedo (2017) ressaltam que o novo conhecimento tem que dar sentido para vida cotidiana do indivíduo, levando em consideração os conhecimentos prévios, pois servirão de âncora para os novos conhecimentos. Portanto, no que tange as percepções dos educandos, é necessário conhecê-las para ajudar na construção de novos conhecimentos e, a partir disso, levá-los à aprendizagem significativa, entendida por nós como a capacidade de aplicar no cotidiano os conhecimentos científicos. Para Ausubel (1968), a aprendizagem significativa estabelece a construção do novo conhecimento a partir dos conhecimentos já estabelecidos na estrutura cognitiva do aprendiz.

$\mathrm{Na}$ segunda semana, os educandos receberam os mesmos frascos da semana anterior e foram orientados a analisar e descrever o que estavam observando. Neste estágio, os frascos apresentavam larvas e pupas. Alguns educandos denominam as pupas com elementos de seu cotidiano. A exemplo disso, a pupa foi comparada a arroz e grãos, como pode ser observado nas seguintes frases:

A9: "observei que tem vários grãos que são pretos e claros e umas larvas"

A7: "vi que tem um monte de arroz uns brancos e outros escuros"

Ainda, no decorrer desta etapa os educandos não conseguiram associar o surgimento das larvas e pupas como parte do ciclo de vida. Entretanto, na sequência das atividades, se identificou a ocorrência de mudanças no conceito de alguns educandos. Foi possível perceber que ao mesmo tempo que associavam as pupas como casca, eles tinham a concepção que poderiam ser ovos, o que, na teoria deles, estavam relacionados ao ciclo de vida da mosca. Essa mudança de conceito pode ser observada nas na Figura 4 e posteriormente nas narrativas dos discentes. 
Figura 4. Teorização: aparecimento de larvas.

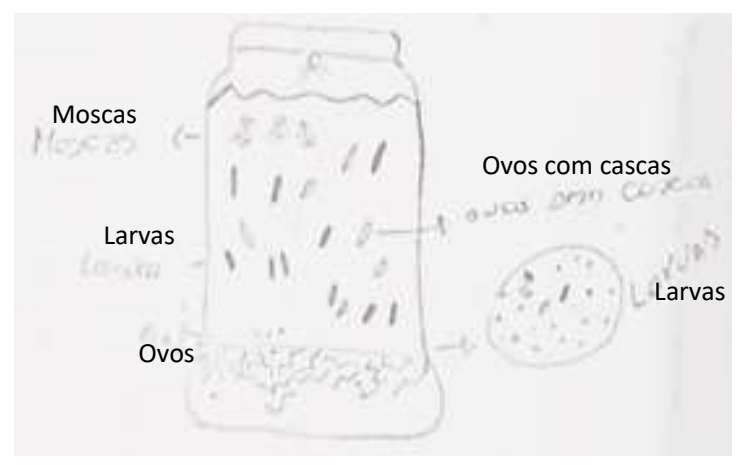

Fonte: Ilustração realizada pelos educandos.

\section{A3: "Observei que tem várias cascas no vidro que podem ser ovos"}

A10: "No pote tem larvas recém-nascidas, algumas são pretas e outras brancas, as pretas podem ser ovos chocando" A15: "Observei hoje que as mosquinhas umas se mexem e outras estão grudadas no vidro e algumas são pretinhas e as outras são brancas. Eu acho que as branquinhas saíram dos ovos pretinhos"

Enfatiza-se que, a partir dos conhecimentos prévios e das novas informações que estavam sendo trabalhadas em sala de aula e com o material de apoio, os questionamentos realizados no decorrer das atividades proporcionaram que os educandos refletissem acerca de suas observações e consequentemente mudassem ou ampliassem seus conceitos. Entretanto, para que ocorra de fato essa mudança de conceitos durante a aprendizagem, cabe o educador entender que os educandos aprendem a partir de suas concepções. De acordo com Taha et al. (2016) é essencial que o docente escute e entenda o que seus educandos querem dizer e permita que possam explicitar seus conhecimentos. Corroborando, Moraes (2010), diz que "aprender é ampliar o mundo em que se vive e reestruturá-lo de forma permanente. Aprender a reconstruir e ampliar seus próprios conhecimentos, as habilidades de interagir com o mundo e por meio disso, reconstruir-se a si próprio (Moraes, 2010, pg. 04).

Diante desse cenário, e no que tange ao Ensino de Ciências, "é preciso criar um ambiente propício para que os alunos caminhem de suas concepções não-científicas às científicas" (Pereira, 2010 p.3). Cabe ressaltar, que é imprescindível levar em consideração o conhecimento prévio dos educandos, independente se essas concepções estão corretas ou não. Durante as atividades, foi possível perceber que os educandos começaram a construir seus próprios conhecimentos a partir de suas experiências e percepções já consolidadas.

Essas (re)construção de conceitos acontece pela ação ou aprender fazendo. Nesse sentido, Freire (1996), fundamentado na pedagogia problematizadora, ressalta que, o que impulsiona a aprendizagem é a resolução de problemas e a construção de novos conhecimentos a partir de experiências prévias. Os educandos aprendem e constroem seus próprios conhecimentos no momento que eles começam a solucionar os problemas propostos a eles.

No entanto, sabendo que é possível estimular o interesse dos educandos pela Ciência, é preciso conhecer diferentes metodologias que incentivem os educandos a construir conhecimentos a partir de seus próprios interesses. Uma ferramenta que pode servir de apoio para o processo de ensino e aprendizagem é a MP/AM. Segundo Copetti et al. (2015), esse método pode conduzir os educandos ao contato com as informações e a produção de conhecimentos, com a finalidade de solucionar os problemas e promover o seu próprio desenvolvimento.

$\mathrm{Na}$ etapa descrita como 'hipóteses de soluções' e 'aplicação da realidade', os estudantes demonstraram uma compreensão sobre o que ocorreu durante as atividades propostas. No final das atividades, os estudantes apesentaram ter conhecimento acerca do ciclo de vida das moscas. É possível observar, por meio do desenho abaixo, todo o processo da atividade proposta, elencando o ciclo de vida desse inseto. Esse entendimento é demonstrado na Figura 5. 
Figura 5. Aplicação da realidade: ciclo de vida.

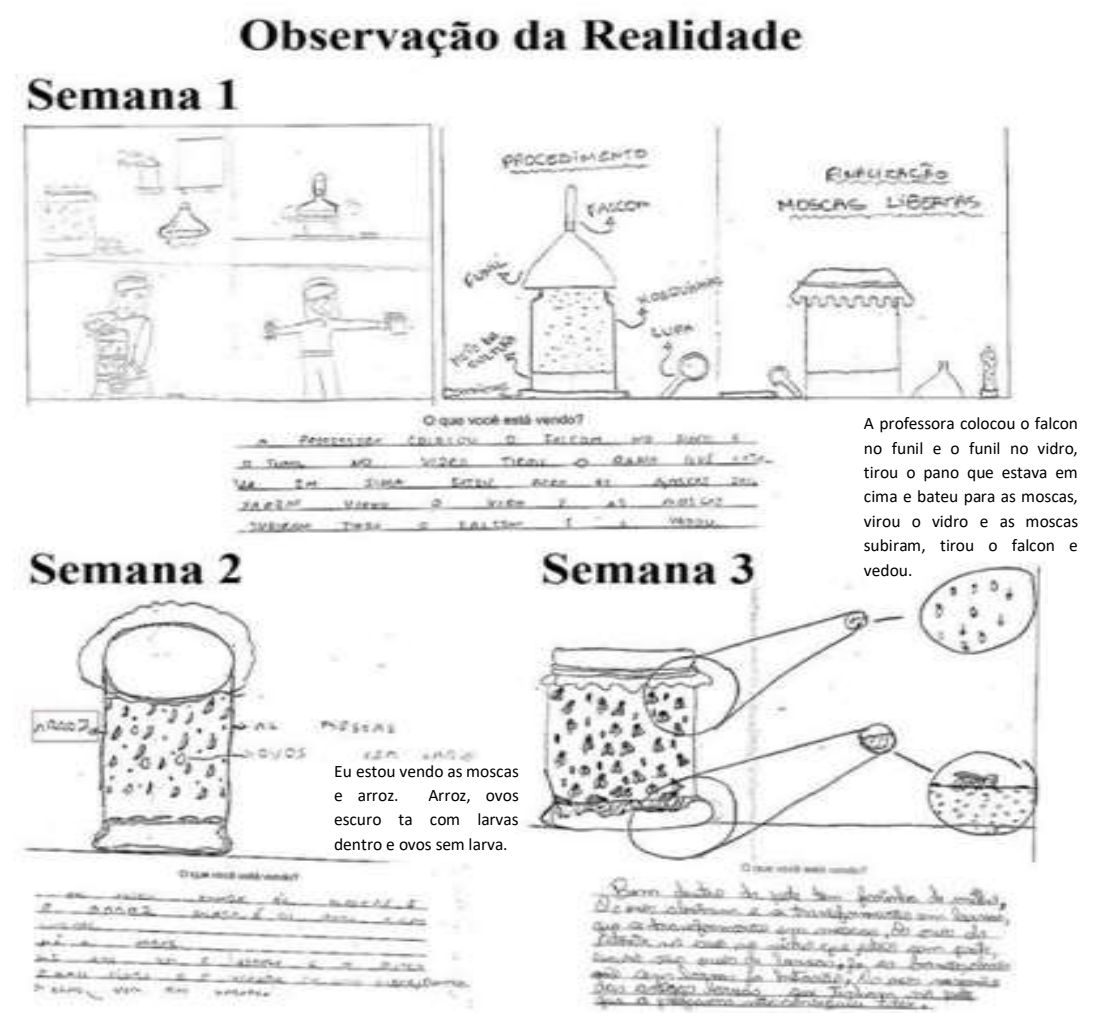

Fonte: Ilustração realizada pelos educandos.

Ainda, foi notório a mudança na concepção dos estudantes sobre o tema trabalhado. No início, os educandos não sabiam responder de onde as moscas surgiram e no final das atividades eles descreveram os acontecimentos como um ciclo, neste caso o ciclo de vida da D. melanogaster. A descrição pode ser observada a seguir:

A11: “As moscas botaram ovos ali no vidro e nasceram as mosquinhas, a casca escura é mosca dentro e a clara já nascendo"

A3: "Quando as outras moscas saíram do pote deixaram os ovos e depois de um tempo os ovos eclodiram”

A22: "No mesmo pote onde as moscas tinham sido liberadas as moscas deixaram os ovos e vimos que viraram larvas e das larvas algumas moscas”,

Com base nos resultados apresentados, infere-se que a atividade despertou a curiosidade e o interesse dos educandos em relação ao modelo didático apresentado. A medida em que os estudantes interagem eles constroem seus próprios conhecimentos e hipóteses para os acontecimentos. Assim, a atividade proposta demonstrou-se pertinente ao ambiente escolar, se configurando como uma importante estratégia para o processo de ensino e aprendizagem. Também pode servir de apoio aos educadores que apresentam dificuldades quando o assunto é ensinar ciclo de vida. De fato, Rocha (2013) aponta que o uso das moscas como estratégia de ensino pode contribuir no processo de ensino e aprendizagem e na construção dos conhecimentos dos educandos. Ainda, o autor ressalta que o uso destas espécies se torna uma alternativa para o ensino de ciências, diante de alguns conteúdos que muitas vezes são de difícil compreensão por parte dos educandos.

\section{Considerações Finais}

A partir dos resultados e com base nas discussões acima, a MP/AM juntamente com o modelo didático aqui proposto 
demonstrou ser eficaz para o ensino do ciclo de vida dos insetos. Quando justaposto com outras estratégias, como as aulas e materiais complementares para pesquisa, possibilita atingir com êxito o processo de ensino e aprendizagem. Ainda, proporcionam aos educandos o desenvolvimento da criticidade, e a construção e reconstrução dos seus próprios conceitos.

A partir dos dados obtidos, entende-se que essa proposta tornou o ensino mais atrativo, prazeroso e relevante, fazendo com que a construção de conhecimento dos educandos tenha sido significativa. Cabe aqui ressaltar que essas estratégias emergem como possibilidade que auxiliam na superação de práticas tradicionais de ensino. Apesar das dificuldades e obstáculos encontrados pelos educadores acerca do Ensino de Ciências, torna-se imprescindível que busquem estratégias e metodologias de ensino, no intuito de usar modelos de ensino- aprendizagem mais dinâmicos e ativos e que despertem o interesse por parte dos educandos.

Dessa forma, a utilização da MP/AM, em conjunto com o modelo D. melanogaster, torna o ensino efetivo, uma vez que o educando se torna ativo na construção do seu próprio conhecimento. Conclui-se, deste modo, que a utilização de diferentes metodologias e estratégias de ensino pode ser uma alternativa para aproximar o Ensino de Ciências do cotidiano dos estudantes, tornando-os autônomos, críticos e reflexivos. Além disso, auxiliando para que esses sujeitos possam atuar com responsabilidade diante da sociedade em que vivem. Ressaltamos também que cabe ao educador possibilitar situações as quais levem os educandos a questionar a própria realidade.

Por fim, ressaltamos que esse trabalho pode ser utilizado no cotidiano docente não apenas como uma das diversas estratégias de prática para o ensino do ciclo de vida de insetos, mas também como um gérmen de cristalização para a busca de alternativas factíveis e realistas para as aulas práticas de Ciências. Além disso, este estudo contribui como alicerce para trabalhos futuros que proponham ou investiguem métodos onde o estudante seja o centro ativo do processo de ensinoaprendizagem.

\section{Agradecimentos}

À Coordenação de Aperfeiçoamento de Pessoal de Nível Superior - CAPES, pelo suporte financeiro.

\section{Referências}

Almeida, D. F. d. (2012). Concepções de alunos do ensino médio sobre a origem das espécies. Ciência \& Educação (Bauru), 18(1), 143-154. https://doi.org/10.1590/s1516-73132012000100009

Ausubel, D. P. (1968). Educational psychology: A cognitive view. Holt Rinehart, \& Winston.

Berbel, N. A. N. (1998). Metodologia da problematização: experiências com questões de ensino superior, ensino médio e clínica. UEL.

Berbel, N. A. N. (2016). A Metodologia da Problematização com o Arco de Maguerez: uma reflexão teórico-espistemológica. EDUEL.

Borges, S T., \& Alencar, G. (2014). Metodologias ativas na promoção da formação crítica do estudante: o uso das metodologias ativas como recurso didático na formação crítica do estudante do ensino superior. Cairu em Revista, (4), 119-143. https://www.ea2.unicamp.br/mdocs-posts/metodologias-ativas-napromocao-da-formacao-critica-do-estudante-o-uso-das-metodologias-ativas-como-recurso-didatico-na-formacao-critica-do-estudante-do-ensino-superior.

Borror, J. D., \& Delong, M. D. (1969). Introdução ao estudo dos insetos. Edgard Bucher.

Chassot, A. (2003). Alfabetização científica: Uma possibilidade para a inclusão social. Revista Brasileira de Educação, (22), 89-100. https://www.scielo.br/scielo.php?script=sci_arttext\&amp;pid=S1413-24782003000100009

Copetti, J., Lanes, K. G., Lara, S., \& Folmer, V. (2015). Capacitação de professores em educação e saúde no contexto escolar por meio da problematização. In Educação e saúde no contexto escolar, v1, (pp. 15-40). Universidade Federal do Pampa.

Folmer, V. (2007). As concepções dos estudantes acerca da natureza do conhecimento científico: Confronto com a experimentação [Dissertação de Mestrado em Educação em Ciências: Química da vida e Saúde não publicada]. Universidade Federal do Rio Grande do Sul.

Freire, P. (1996). Pedagogia da autonomia: Saberes necessários à prática educativa. Paz e Terra.

Gil, A. C. (2002). Como elaborar projetos de pesquisa (6a ed.). Atlas. 
Gomes, R. A. P. L. (2001). Protocolo de Utilização de Drosophila em genética: $1^{\circ}$ parte. Departamento Biologia Vegetal da Faculdade de Ciências da Universidade de Lisboa. http://ordembiologos.pt/wp-content/uploads/2015/11/Drosophila-01Jan01.pdf>.

Lima, G. H. de., Silva, R. S. da., Arandas, M. J. G., Junior, N. B. d. L., Cândido, J. H. B., \& Santos, i. R. P. d. (2016). O uso de atividades práticas no ensino de ciências em escola pública do município de Vitoria Antão. Revista Ciência em Extensão, 12(1), 19-27. https://ojs.unesp.br/index.php/revista_proex/article/view/1190/1188.

Liu, Q.-T., Liu, B.-W., \& Lin, Y.-R. (2818). The influence of prior knowledge and collaborative online learning environment on students' argumentation in descriptive and theoretical. Scientific Concept International Journal of Science Education, 41(2), 165-187.

Martins, J. L., Goulart, A. da S., \& Dinardi, A. J. (2020). O Ensino de Botânica no ensino fundamental: percepções e análise de uma estratégia de ensino. Research, Society and Development, 9(5), e98953173. https://doi.org/10.33448/rsd-v9i5.3173

Moraes, R. (2010). O significado de aprender: Linguagem e pesquisa na reconstrução do conhecimento. Caxias do Sul: Conjectura, 15(1).

Nascimento, M. B. do ., Santana, L. F. ., Rosa, W. F. ., Paris, M. da C. ., \& Gabriel, K. F. de O. (2022). The importance of active methodologies in the learning of Higher Education. Research, Society and Development, 11(1), e41711125026. https://doi.org/10.33448/rsd-v11i1.25026

Morán, J. (2015). Mudando a educação com metodologias ativas. In Convergências midiáticas, educação e cidadania: Aproximações jovens. PROEX/UEPG. Paiva, M. R. F., Parente, J. R. F., Brandão, I. R., \& Queiroz, A. H. B. (2016). Metodologias ativas de ensino-aprendizagem: Revisão integrativa. SANARE: Revista de Políticas Públicas, Sobral (CE), 15(2).

Pereira, B. B. (2010). Experimentação no ensino de ciências e o papel do professor na construção do conhecimento. Cadernos da FUCAMP, 9(11).

Pinto, T. L. F., \& Uieda, V. S. (2007). Invertebrados Caracteres Morfológicos, Fisiológicos e Ecológicos: produção de material didático para o ensino fundamental. In PINHO, S. Z.; SAGLIETTI, J. R. C. (org.). Núcleos de Ensino. Unesp.

Prado, M. L. do., Velho, M. B., Espindola, D. S., Sobrinho, S. H., \& Backes, V. M. S. (2012). Arco de Charles Maguerez: Refletindo estratégias de metodologia ativa na formação de profissionais de saúde. Escola Anna Nery Revista de Enfermagem, 16(1), 172-177. https://www.scielo.br/pdf/ean/v16n1/v16n1a23.pdf

Rocha, L. D. L. S, Faria, J. C. N. de M., Cruz, A. H. da S., Reis, A. A. da S., \& Santos, R. d S. (2013). Drosophila: um importante modelo biológico para a pesquisa e o ensino de genética. Scire Salutis, 3(1), 37-48. http://www.sustenere.co/index.php/sciresalutis/article/view/ESS2236-9600.2013.001.0004/234>.

Salgueiro, A. C. F., Goulart, A. da S., Viçosa, D. L.; Viçosa, C. S. C. L., \& Folmer, V. (2018). Resolução de problemas no ensino de Ciências: utilização de Artemia salina como modelo experimental para o estudo de plantas medicinais na escola básica. Revista Ensino de Bioquímica,16 (2), 31-47. http://bioquimica.org.br/revista/ojs/index.php/REB/article/view/814/654.

Santos, R. E. do.; \& Macedo, G. E. L. de. (2017). Aprendizagem significativa de conceitos botânicos em uma classe de jovens e adultos: análise dos conhecimentos prévios. Revista Contexto \& Educação, 32(101), 105-124. https://www.revistas.unijui.edu.br/index.php/contextoeducacao/article/view/6236>.

Shulman, L. S. (2014). Conhecimento e ensino: fundamentos para a nova reforma. Cadernoscenpec, 4(2), 196-229. https://www2.uepg.br//programa-des/wp content/uploads/sites/32/2019/08/SHULMANN-sobre-ENSINO.pdf>.

Somavilla, A. S., \& Zara, R. A. (2016). Ciências e o ensino de Ciências no Brasil. Experiências em Ensino de Ciências, 11(3), 118-127. https://if.ufmt.br/eenci/artigos/Artigo_ID326/v11_n3_a2016.pdf>.

Sousa, C. L. de ., Duarte, C. T. de S., Azevedo, M. M. R., Hager, A. X. ., Figueira, A. A. ., Pacheco, A. ., Oliveira, P. L. das N. de ., Silva , A. C. da ., Pereira, P. G. ., Maia , M. V. P. ., Dorabiato, M. D. ., \& Lages, S. M. . (2022). Playful strategy in the Science teaching and learning process in a public school in Santarém-PA. Research, Society and Development, 11(1), e13011124364. https://doi.org/10.33448/rsd-v11i1.24364.

Taha, M. S., Lopes, C. S. C., Soares, E. de L., \& Folmer, V. (2016). Experimentação como ferramenta pedagógica para o ensino de ciências. Experiência em Ensino de Ciências, 11(1), 138-154. https://if.ufmt.br/eenci/artigos/Artigo_ID305/v11_n1_a2016.pdf >.

Vasconcelos, L. L. P. M., \& Neres, J. C. I. (2021). Aplicabilidade do Ensino de Ciências Baseado em Investigação em uma escola pública de ensino fundamental de Guaraí-TO. Research, Society and Development, 10(16), e572101624243. https://doi.org/10.33448/rsd-v10i16.24243

Viçosa, C. S. C. L., Taha, M. S., Soares, E. de L., \& Ferreira, F. d S. (2016). Unidade de aprendizagem: desenvolvendo a cidadania através da temática trânsito. Revista Ciências \& Ideias, 7(3), 88-100. https://revistascientificas.ifrj.edu.br/revista/index.php/reci/article/view/574>. 